
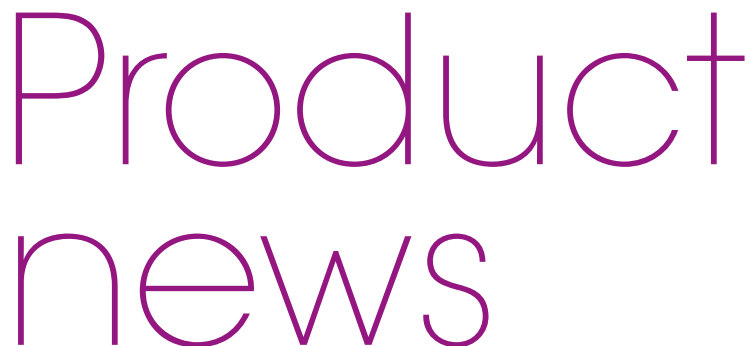

Product news is provided as a service to readers using text and images from the manufacturer, supplier or distributor and does not imply endorsement by BDJ Team. Normal and prudent research should be exercised before purchase or use of any product mentioned.

\title{
EXCITING NEW SOCIAL NETWORKING SITE LAUNCHES
}

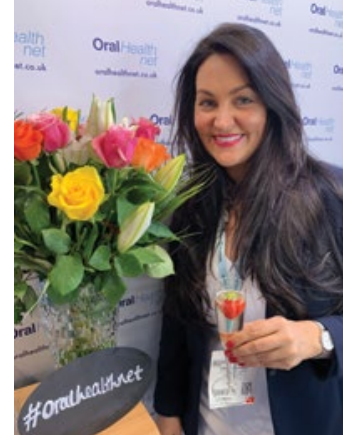

A unique online platform created to facilitate networking between dental professionals and patients has arrived in the form of OralHealthNet

It was launched at the British Dental Conference and Dentistry Show on 18 May 2019.

Registration is free, enabling OralHealthNet members (both individuals and clinics) to post a photo, contact details of their practice and their educational background. Further facilities are available for a small fee and right now the site is running a special deal, offering incredible value.

For anyone who signs up before the end of June 2019 , a one-off payment of $£ 50$ will cover them until 1 January 2020, essentially offering four months free during the roll-out of the website as it is introduced to consumers.

Ordinarily, the cost will be $£ 25$ per month to add treatments, services, prices, more photos, a social media news feed and a website link, as well as a way to make direct contact without exposing personal details, or $£ 50$ for the added extra of a live booking facility and to add videos

Speaking about the launch, Vaida Buksnaityte, Founder and CEO of the OralHealthNet project and a practising hygienist (pictured), commented: 'I am delighted to be able to invite fellow dental professionals to join me in this incredibly important project, strengthening ties within the dental team and with patients. This has been a personal project of mine for about five years now, and my blogs have an active following with around 14,000 readers, so the site is already a hive of activity.

'I have ambitious plans, including member benefits and events etc, which will be announced in the coming months. Some of the UK's top dentists and hygienists are already signed up, and I would love every dental professional to join us.'

This is your chance to showcase your talents and educate consumers about your services within this dedicated community, growing your patient base and building stronger relationships.

For further information, visit oralhealthnet. co.uk or email info@oralhealthnet.co.uk.

\section{DON'T GET BOGGED DOWN IN ADMIN}

Banish software updates and lengthy IT admin: with Dentally dental practitioners can run faster reports, enjoy efficient charting and all the benefits of simple patient management. So, you get more time doing what you love: helping patients!

Dentally is committed to developing and innovating new ways of making dental practice software simple and easy to use. Time saving product updates introduced over the past few weeks include new reporting, improvements to charting, new waiting lists functionality and updates to the iPad app.

Dentally is trusted by over 4,000 dental professionals in the UK and abroad, who work smarter, work remotely and work securely. For more information visit: http:// info.dentally.co/be-on-cloud-9 or email hello@dentally.co.

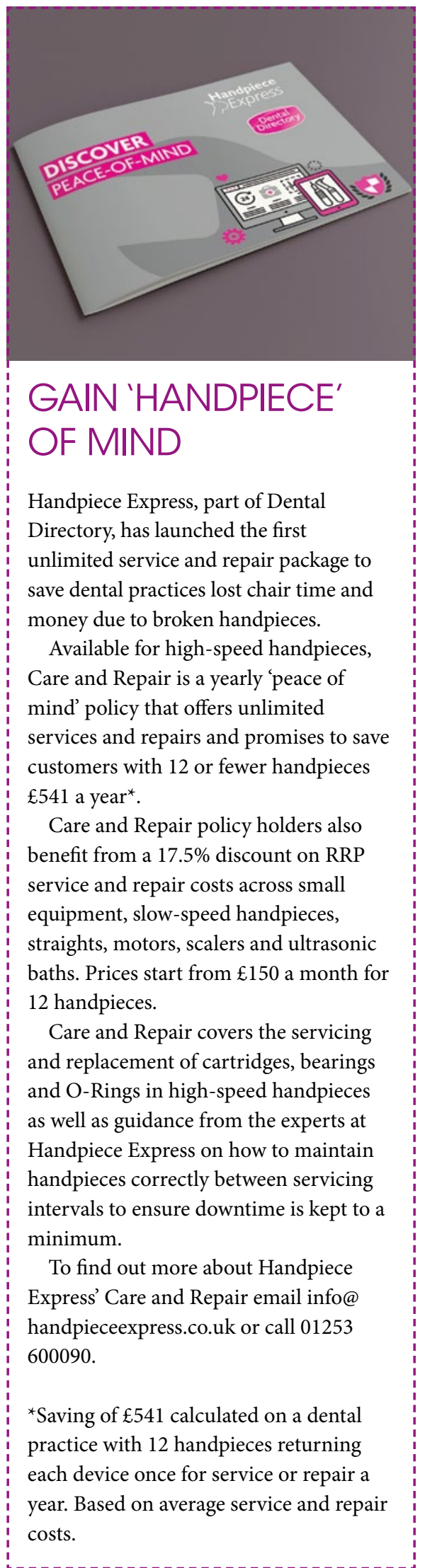

If you would like to promote your products or services direct to the dental industry in BDJ Team, call Andy May on 02078434785 or emaila.may@nature.com 